\title{
Article \\ Shape and Spacing Effects on Curvy Twin Sail for Autonomous Sailing Drone
}

\author{
Minh Ngoc Pham ${ }^{1}$, Inho Ryu' ${ }^{2}$ Bugi Kim³ ${ }^{3}$ Changjo Yang 4,* \\ 1 Graduate School of Mokpo National Maritime University; pmn5d16@gmail.com \\ 2 Graduate School of Mokpo National Maritime University; imiim@mmu.ac.kr \\ 3 Division of Mechatronics Engineering, Mokpo National Maritime University; kim60091@mmu.ac.kr \\ 4 Division of Marine Engineering System, Mokpo National Maritime University; cjyang@mmu.ac.kr \\ * Correspondence: cjyang@mmu.ac.kr; Tel: +82-10-9901-0876
}

\begin{abstract}
There is an accelerating requirement for ocean sensing where autonomous vehicles can play an essential role in assisting engineers, researchers, and scientists with environmental monitoring and collecting oceanographic data. This paper is performed to develop a rigid sail for the autonomous sailing drone. Our study aims to numerically analyze the aerodynamic characteristics of curvy twin sail and compare it with wing sail. Because racing regulations limit the sail shape, only the two-dimensional geometry was open for an optimization. Therefore, this study's first objective was to identify the aerodynamic performance of such curvy twin sails. Simultaneously, a secondary objective was to estimate the effect of the sail's spacing and shapes. A viscous Navier-Stokes flow solver is used for the numerical aerodynamic analysis. The 2D aerodynamic investigation is a preliminary evaluation. The results have shown that the curvy twin sail designs have improved lift, drag, and driving force coefficient compared to the wing sails. The spacing between the port and starboard sails of curvy twin sail is an important parameter. The spacing is $0.035 \mathrm{~L}, 0.07 \mathrm{~L}$, and $0.14 \mathrm{~L}$ shows the lift coefficient reduction because of dramatically stall effect, while flow separation is improved with spacing is $0.21 \mathrm{~L}, 0.28 \mathrm{~L}$, and $0.35 \mathrm{~L}$. Significantly, the spacing $0.28 \mathrm{~L}$ shows the maximum high pressure at the lower area and the small low pressure area at leading edges, so the highest lift is generated.
\end{abstract}

Keywords: Sailing Drone, Curvy Twin Sail, Driving Force Coefficient, Apparent Wind, Angle of Attack.

\section{Introduction}

The marine environment in the sea is facing problems such as eutrophication, acidification, and oxygen deficiency. The need is growing for ocean sensing to benefit marine safety, environmental monitoring and climate research. An unmanned autonomous vehicle that can assist surveying the sea by acquiring long-term placed bound measurements, reporting pollution, hydrographic and meteorological data could be a helpful and cheap alternative to a commercial research vessel.

The researchers are now developing an autonomous sailing drone, which will be used as an experimental platform for autonomous data acquisition in the sea. The application drives requirements on the vehicle, where it needs to have robustness, reliability, and energy efficiency. The requirement is to develop a vehicle that can survive in any weather conditions all year under free conditions.

Utilization of wing sails in autonomous sailing drones has been an object for research in maritime robotics for over 15 years. Researches on wing sails have been conducted by many researchers. Several attempts to develop such systems have been made, for instance, by (Elkaim, 2001) and (Neal \& Sauze, 2008) [1, 2]. Elkaim has completed experimental aerodynamic performance of self-trimming wing sail for autonomous surface vehicles [3]. In 2008, Aberystwyth University designed a sailing robot using double wing sail as an aero-propulsion system [4]. A vehicle called "Sail drone" has been launched (Jekins, Meinig, Lawrenece-Salavas, \& Tabisola, 2015) [5]. BMW 
Oracle was updated by a 60-meter high, multi-element wing sail, which won the 33 ${ }^{\text {rd }}$ America's Cup in 2010. The rigid wing sail's flexible size and excellent performance have been paid attention by the shipping industry [6]. Recently, Sweden Research Group have developed an autonomous sailboat with free-rotating wing sail [7]. The research in the field shows that wing sails have good aerodynamic performance, good control capabilities, precision, and low power consumption. In order to improve the aerodynamic performance characteristic, different methods are used, such as trailing flap [8, 9], leading slat [10], deformed flaps [11], and leading-edge turbulences [12], etc. However, difficulties in designing wing sails for autonomous sailing drone has been identified. Because of working in the long term autonomous oceanography, the rigid sail's simple design and good aerodynamic performance are required. Therefore, the workability improvement of the sail in aerodynamic performance must be considered. A two dimensional curvy twin sail which installed on a Sailing drone is proposed and preliminary investigated.

\section{Methods}

\subsection{The Geometry of the Curvy twin sail}

The general specifications of Sailing Drone are presented in Figure 1 and Table 1.
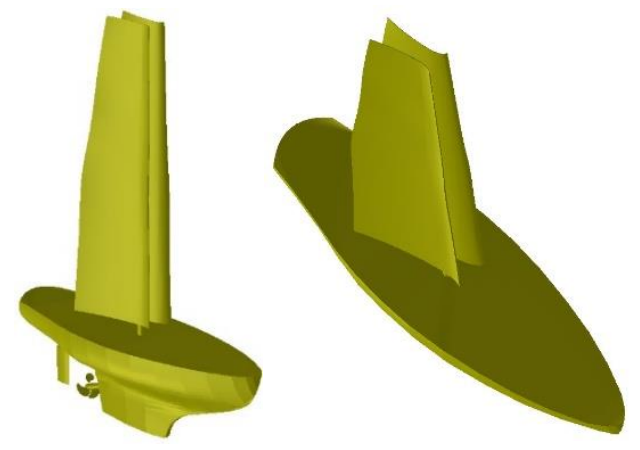

Figure 1 3D Design Model of Sailing Drone

Table 1. General specifications

\begin{tabular}{cc}
\hline \multicolumn{2}{c}{ General Specifications } \\
\hline Length overall & $4.2 \mathrm{~m}$ \\
\hline Width & $1.2 \mathrm{~m}$ \\
\hline Depth & $1.0 \mathrm{~m}$ \\
\hline Height above waterline & $4.0 \mathrm{~m}$ \\
\hline Displacement & $280 \mathrm{~kg}$ \\
\hline Curvy twin sail \\
\hline Span & $3.5 \mathrm{~m}$ \\
\hline Area & $3.0 \mathrm{~m}{ }^{2}$ \\
\hline Material & CFRP
\end{tabular}

The curvy twin sail's geometry is a simplified 2D configuration of two-element rigid sail as Figure 2 and Table 2. The non-dimensional number for characterizing the flow of fluid, Reynolds number is defined by Equation (1):

$$
\operatorname{Re}=\rho v L / \mu
$$

Where $\mu$ is the viscosity coefficient of air, no experimental data of optimized sail was available to validate the numerical results. Therefore, a proper numerical setting was performed to produce 
reliable results. The aerodynamic of NACA 0018 based on experiments were simulated with $\operatorname{Re}=$ $6 \times 10^{5}$ (the wind speed is assumed $8 \mathrm{~m} / \mathrm{s}$ ). Moreover, NACA 0018 was used to develop a wing sail by The Royal Institute Technology. The NACA 0018 wing sail simulation is compared with the curvy twin sail.

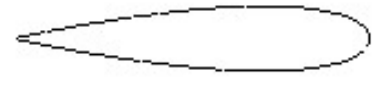

(a)

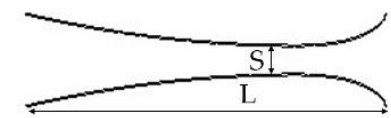

(b)

Figure 2 (a) NACA 0018; (b) Curvy Twin Sail

Table 2. Curvy twin sail parameterization

\begin{tabular}{cc}
\hline L & $0.95 \mathrm{~m}$ \\
\hline $\mathbf{S}$ & $0.02 \mathrm{~m}$ \\
\hline $\boldsymbol{R e}$ & $6 \times 10^{5}$
\end{tabular}

The total aerodynamic force can be decomposed in two ways. The first method considers the driving $\left(\mathrm{F}_{\mathrm{R}}\right)$ and heeling $\left(\mathrm{F}_{\mathrm{H}}\right)$ components of the total force. This is used when studying the balance of the aero-hydrodynamic forces. Nevertheless, when the aerodynamic behavior is analyzed on its own, it is common practice to decompose the aerodynamic force in its lift (L) and drag (D) components, as plotted in Figure 3.

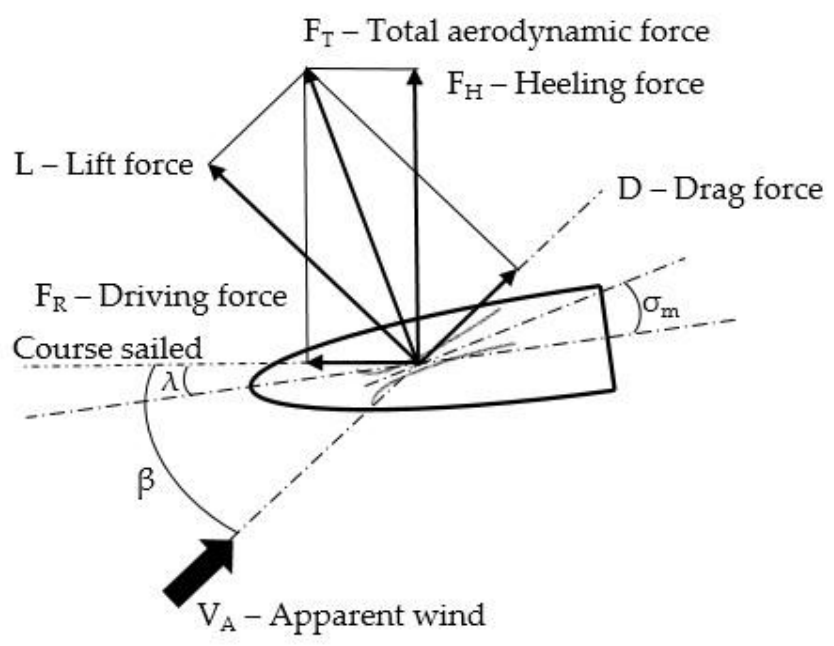

Figure 3 Components of total aerodynamic force

$$
\begin{aligned}
& F_{R}=L \sin \beta-D \cos \beta \\
& F_{H}=L \cos \beta+D \sin \beta
\end{aligned}
$$

It is obvious that the goal is to maximize the driving force and simultaneously minimize the heeling force. When beating against the wind, the drag's contribution is negative because it increases the heeling force and reduces the driving forces. Therefore, in this point of sail, the objective is to maximize the lift and minimize the drag. As the apparent wind angle increases through the reaching point of sail, the drag's contribution to the driving force becomes more important. At the last stage, when downwind, the maximum driving force will equivalent to maximum drag.

This work's primary purpose is to study the sail's shape and spacing, which are considered optimized parameters. By two dimensional simulation, the aerodynamic performance of 5 different sail shape was carried out to find the most appropriate curvy shape and spacing. The aerodynamic of NACA 0018 based on experiments were simulated. Moreover, NACA 0018 was used to develop a 
wing sail by The Royal Institute Technology [7]. The NACA 0018 simulation is compared with the two dimensional curvy twin sail.

\subsection{Computational Approach}

\section{Computational Domain}

The calculation domain for computational simulation is presented in Figure 4. The sail is located at the origin, while a semi-circle of radius $15 \mathrm{~L}$ forms the inlet. The cross-stream domain width is 30L, while the down-stream length is 40L. These domain dimensions ensure domain-independent results [13, 14 and 15]. AOA is adjusted by rotating the direction of airflow. The boundary conditions are described in Table 3. The boundary conditions on domain sides are symmetry, while the downstream boundary is outlet. The velocity at the inlet is uniform, and the value is the same as the free flow velocity.

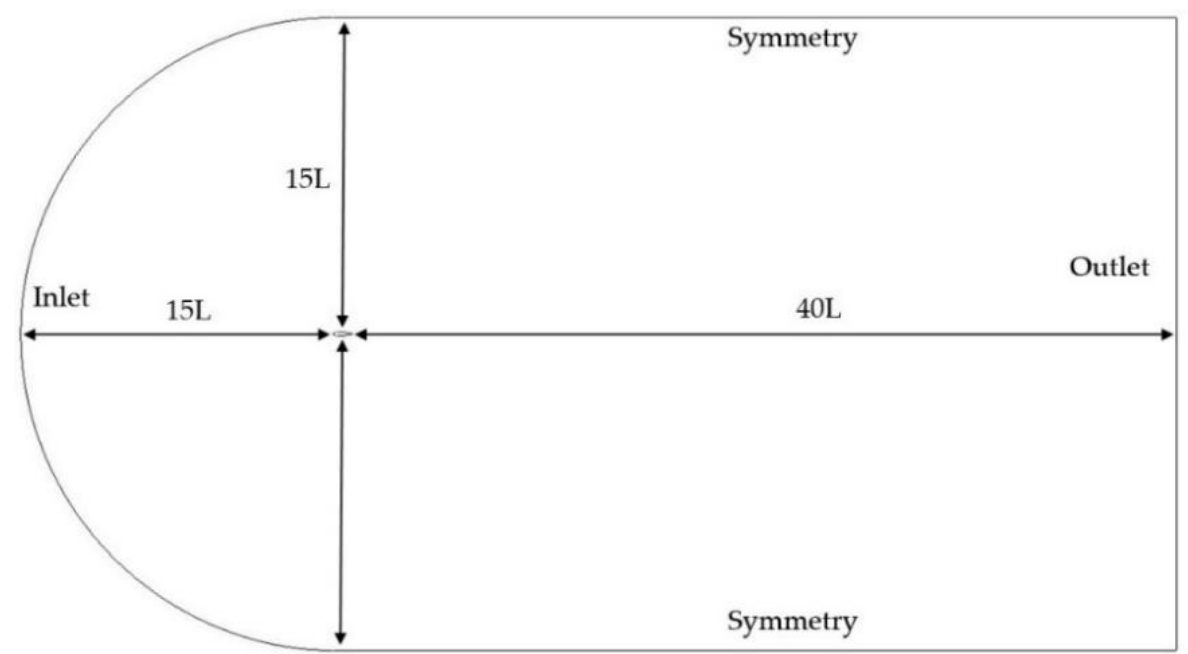

Figure 4 The computational domain

Table 3. Boundary conditions

\begin{tabular}{cc}
\hline \multicolumn{2}{c}{ Calculation domain setup } \\
\hline Inlet & Velocity inlet $(\mathrm{v}=8 \mathrm{~m} / \mathrm{s})$ \\
\hline Outlet & Pressure outlet \\
\hline Top and bottom & Symmetry \\
\hline Wall & No slip \\
\hline
\end{tabular}

Mesh details and mesh independence

The quality of mesh determines the numerical result's accuracy. Different numerical mesh parameters were examined, and a mesh independency test was done by observing the value of the computed lift coefficient at an angle of attack of 5 degrees. Figure 5 shows the adopted mesh shapes where structured mesh was used [16, 17]. The mesh distribution following the hexahedral was also refined to obtain accurate results.

Table 4 shows the obtained lift coefficient of the NACA 0018 at an angle of attack of 5 for different mesh sizes included in the mesh independency test. The computed lift coefficient varies from 0.45888 for mesh 1 to 0.4825 for mesh 4 . The difference between the lift coefficient obtained by the coarse mesh and fine mesh (mesh 1 and mesh 4 ) is 5\%. However, the difference between mesh 4 results and mesh 3 results is only $0.18 \%$. Therefore, mesh 3 is adopted throughout the present work. 


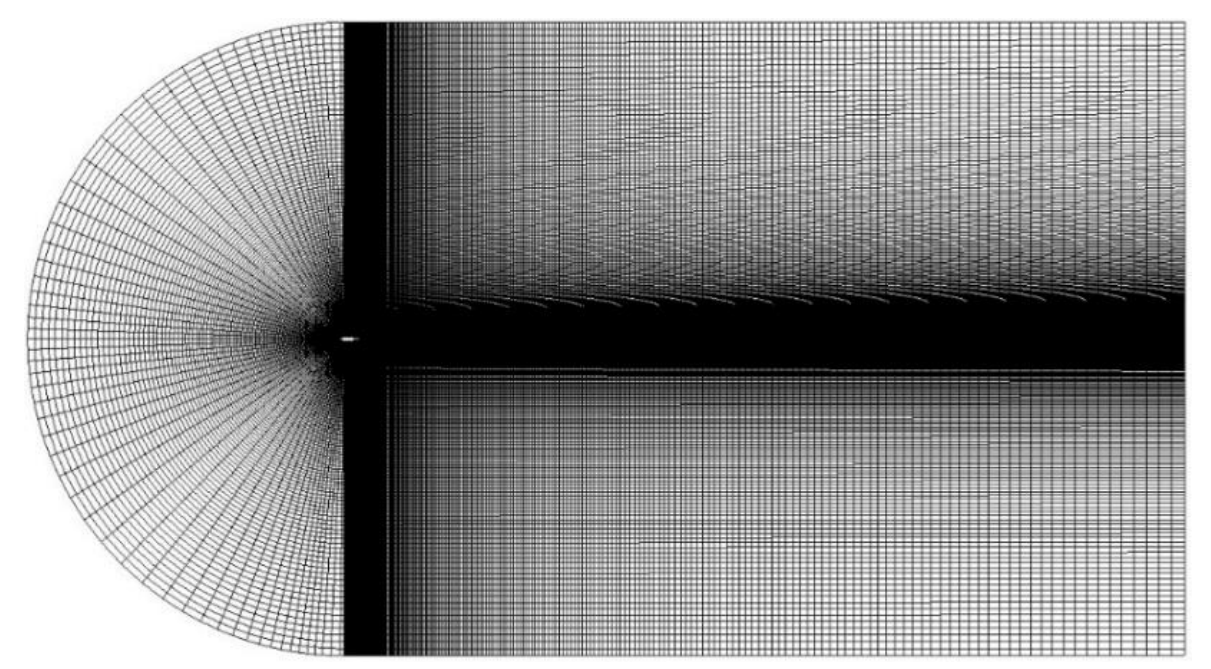

Figure 5 The numerical solution mesh shape

Table 4. Results of the mesh independency test

\begin{tabular}{ccccc}
\hline Mesh Parameter & Mesh 1 & Mesh 2 & Mesh 3 & Mesh 4 \\
\hline No of nodes & 98,868 & 99,023 & 102,912 & 150,671 \\
\hline Lift coefficient & 0.4588 & 0.4801 & 0.4812 & 0.4825 \\
\hline
\end{tabular}

\subsection{Computational Approach}

To investigate the flow phenomena, an appropriate CFD flow solver must be selected. A CFD commercial code software is used to simulate in a parallel computation environment, along with a module for partitioning the volumetric grid as a pre-processor in parallel flow computations. CFD software solver can provide direct flow solutions and ad joint solutions for potential, Euler, NavierStokes, and Reynolds Averaged Navier-Stokes (RANS) governing equations. It uses a Finite Volume Method (FVM) for spatial discretization. Both explicit and implicit methods are available for time integration, and central difference or upwind methods can also be used for spatial discretization. The advanced numerical techniques of residual smoothing and structured mesh methods are also available to improve the robustness and convergence of the flow solution. For the numerical analysis, the solver for the two-dimensional k-epsilon realizable governing equations which describe the mass conservation, momentum, and energy in a viscous fluid was used $[18,19]$. The flow around the sail has a very low speed. It is important to consider the viscous effect for a more accurate flow solution. The setup for the computational model is illustrated in Table 5 [20, 21, and 22].

Table 5. Computational model setup

\begin{tabular}{cc}
\hline Simulation type & Single phase flow \\
\hline Turbulence model & Realizable $k$-epsilon \\
\hline Acting fluid & Air at $25^{\circ} \mathrm{C}$ \\
\hline Calculation type & Steady state \\
\hline
\end{tabular}

Computational model validation

In order to verify the numerical results, the lift coefficient of the two dimensional NACA 0018 wing sail model in a free flow environment is compared with the experimental results. Figure 6 shows the predicted variation of $C_{L}$ with AOA for the NACA 0018 using the realizable $k$-epsilon turbulence models. A comparison with the experimental results [23], also included in Figure 6, shows that the model is in close agreement with the experiments for AOA varying from 0 to 14 degrees. Therefore, the realizable $k$-epsilon turbulence model is selected for further simulations. 


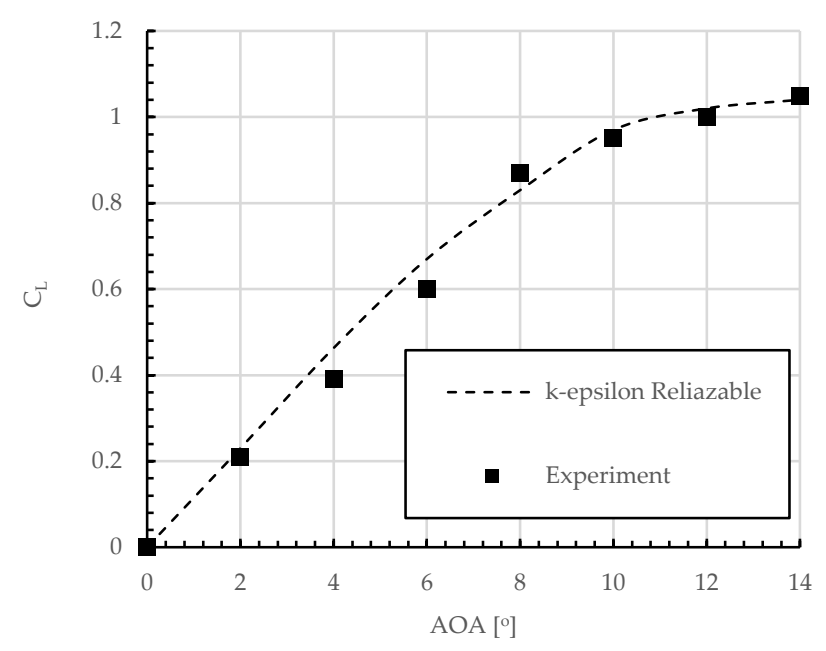

Figure 6 Computed variation of lift coefficient with angle of attack for NACA airfoil, compared with experimental measurements

\section{Results and discussions}

\subsection{Shape Optimizations}

The shape optimization was illustrated in Figure 7. The curvy twin sail's shapes was chosen randomly.

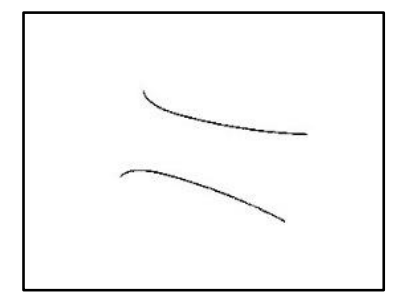

(a)

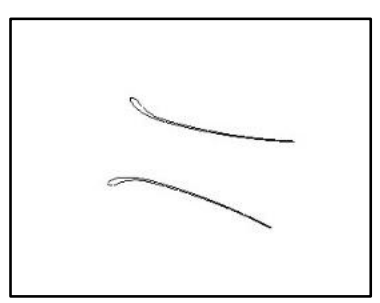

(d)

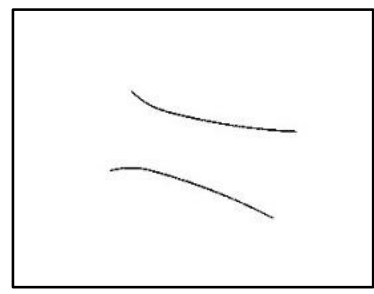

(b)

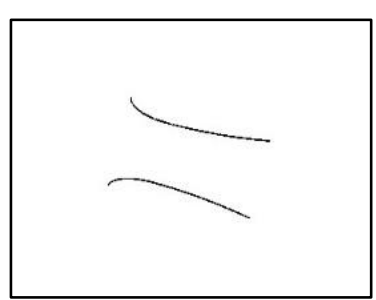

(e)

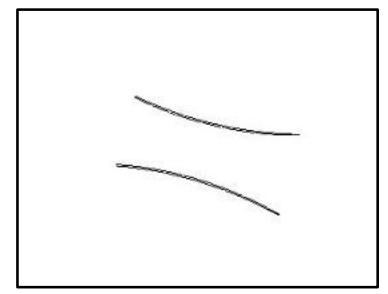

(c)

Figure 7 Optimized Shape Cases Study;

(a) Case 1-1; (b) Case 1-2; (c) Case 1-3; (d) Case 1-4; (e) Case 1-5

\subsubsection{Aerodynamic Performance}

Firstly, the lift and drag coefficients are investigated. Figure 8 illustrates the predicted lift and drag coefficients with different sail shapes. To evaluate the performance of curvy twin sail designs, they have been compared with the NACA 0018 wing sail. 


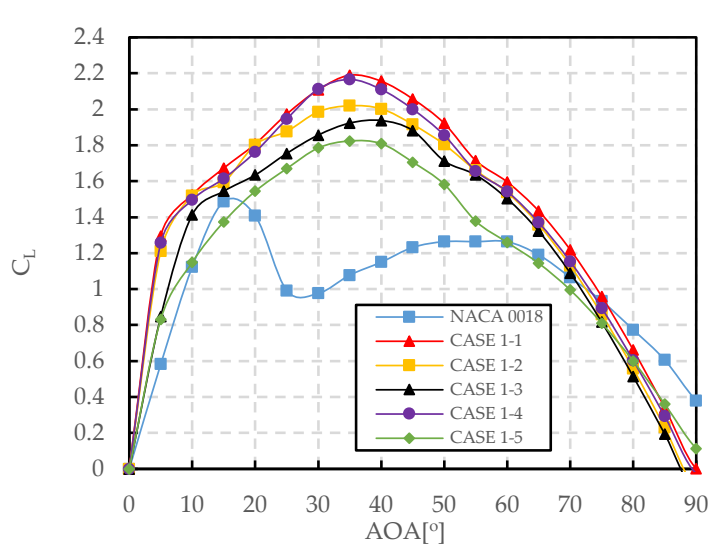

(a)

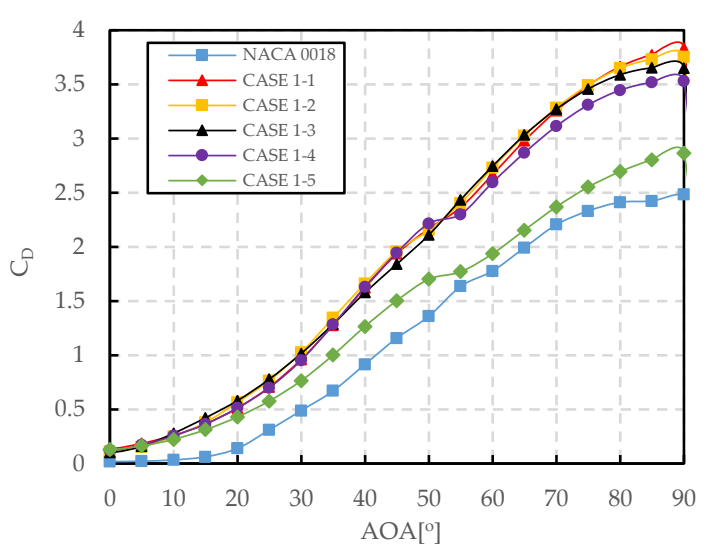

(b)

Figure 8 Effect of shape modifications on lift and drag coefficients

(a) Lift coefficient; (b) Drag coefficient

The curvy twin sail's lift and drag coefficients are superior to the NACA 0018 wing sail. When the angle of attack is from $0^{\circ}$ to $75^{\circ}$, the lift coefficient of curvy twin sails is higher than NACA wing sail. The maximum lift coefficient of the NACA 0018 wing sail is 1.5 with AOA $=15^{\circ}$ while the curvy twin sails are about 2 with AOA around 35. However, due to the curvy shape, the comprehensive performance of curvy twin sail in case 1-1 is higher than others. Therefore, it is necessary to consider sail shape when choosing the shape parameters. Because the curvy twin sail's lift is generated by lift of sail's two components consisting of starboard and port sails, the lift coefficients need to be investigated separately, as shown in Figure 9. Although the drag coefficient in curvy twin sail designs is higher than NACA 0018 wingsail, the drag may also form part of the propulsion force for the sailing drone in downwind conditions. So the aerodynamic performance for the curvy twin sail propose in this paper is more excellent.
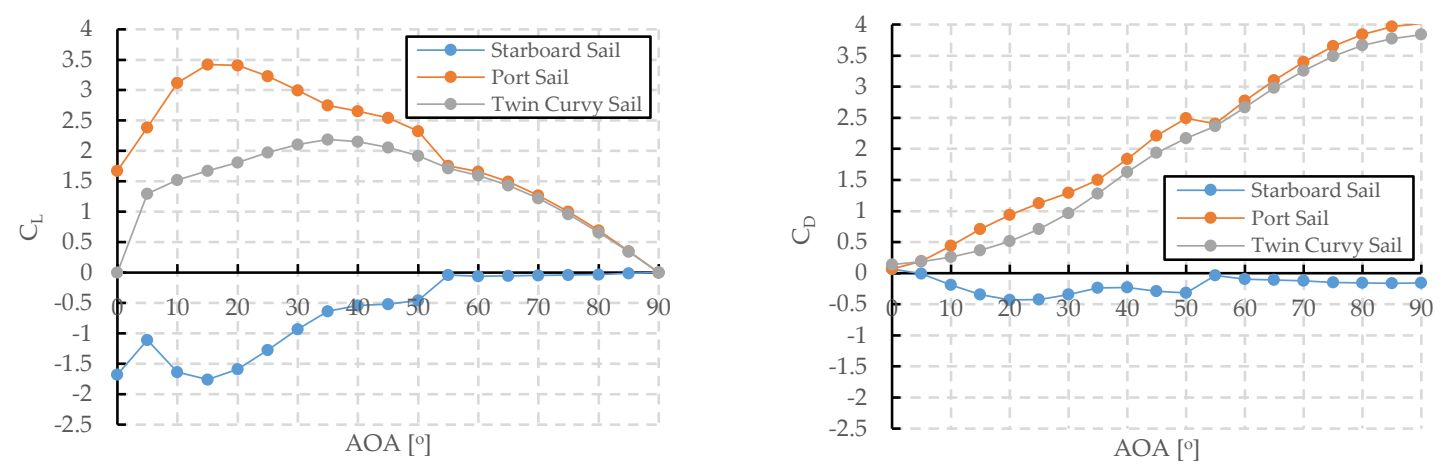

(a)
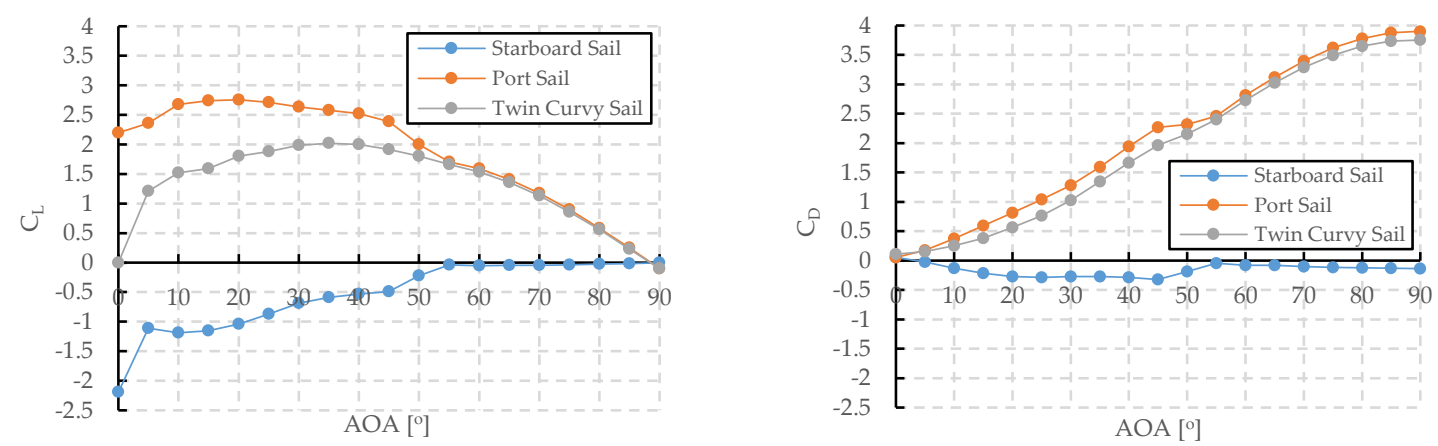

(b) 

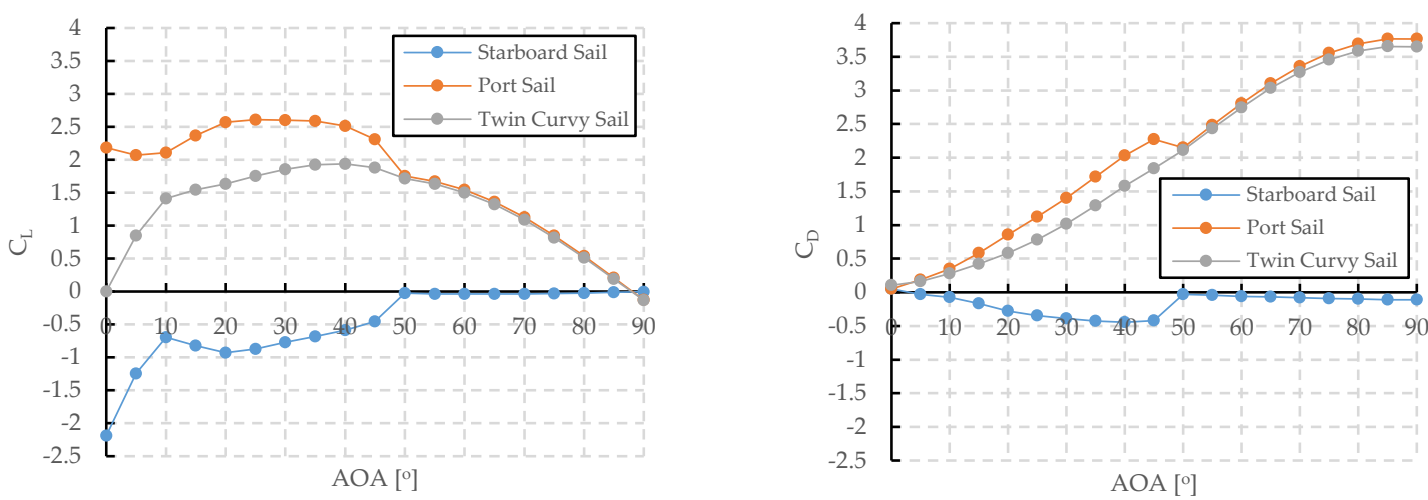

(c)
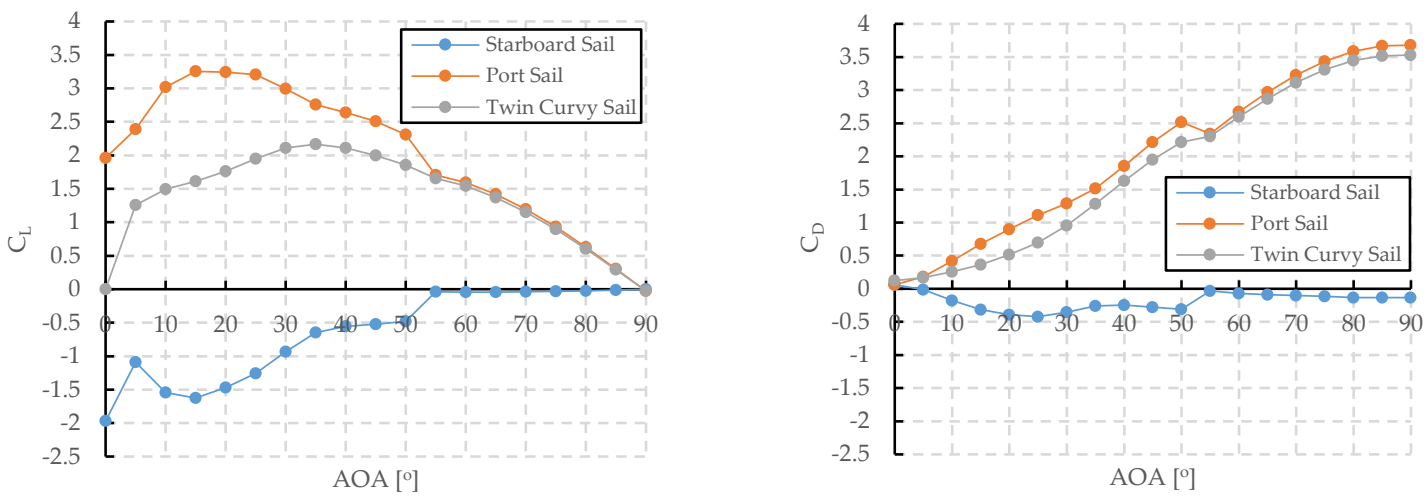

(d)
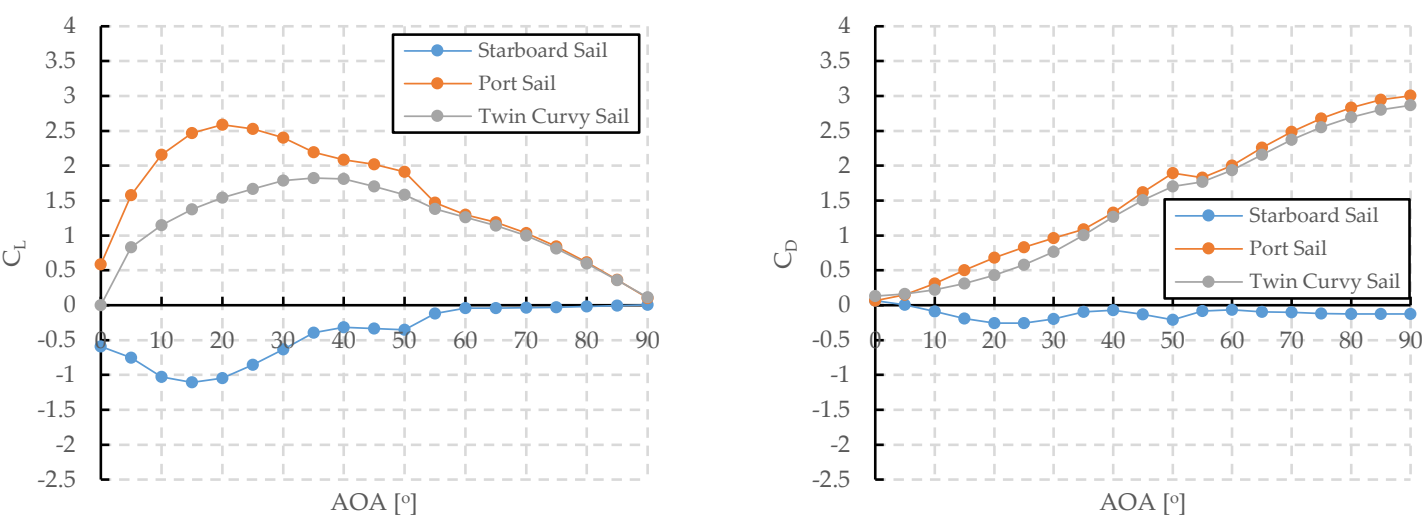

(e)

Figure 9 Lift and Drag coefficients for port and starboard sails; (a) Case 1-1; (b) Case 1-2; (c) Case 1-3; (d)

$$
\text { Case 1-4; (e) Case 1-5 }
$$

The port sail mainly creates the favorable lift force while the starboard sail makes an adverse lift in starboard wind conditions. In contrast, the function of port and starboard sails are interchangeable in port wind conditions. It is convenient only to consider working in starboard wind conditions. The lift coefficient of port sail reaches a peak when the angle of attack is around $15^{\circ}$, but the total lift coefficient is not maximum. It is attributed to the starboard sail generated dramatic minor lift. When the angle of attack is over 55\%, the starboard sail is not effected on the lift coefficient. Although there are unequal lifts at the port and starboard sail in curvy twin sail' case optimization, the difference in drag among them is unremarkable. 


\subsubsection{Velocity streamlines and pressure contours}

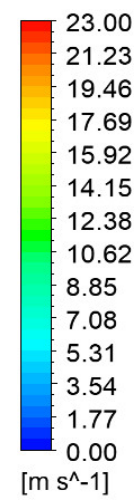

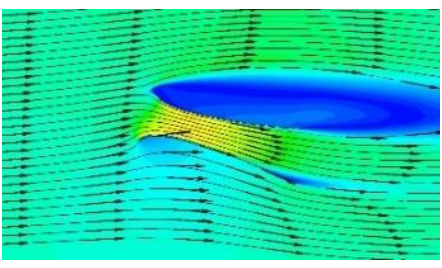

(b)

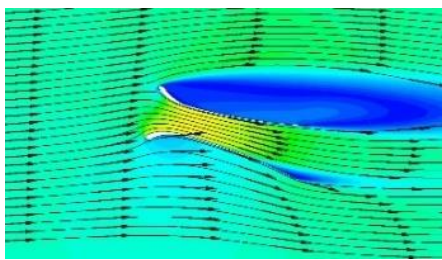

(e)

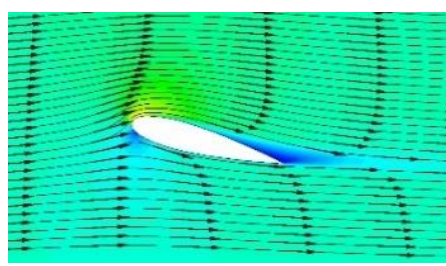

(a)

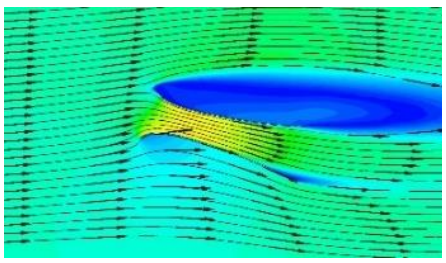

(c)

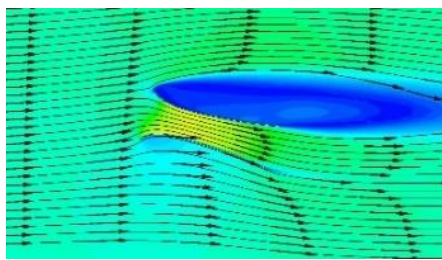

(f)

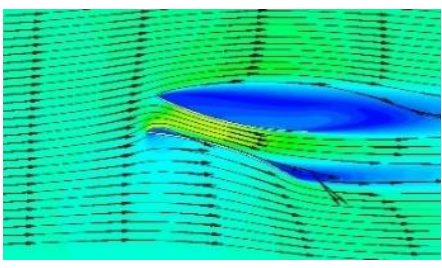

(d)

Figure 10 Velocity contours and streamline at $\mathrm{AOA}=15^{\circ}$; (a) NACA 0018; (b) Case 1-1; (c) Case 1-2;

(d) Case 1-3; (e) Case 1-4; (f) Case 1-5

The curvy twin sail with different shapes and NACA 0018 wing sail at $\mathrm{AOA}=15^{\circ} ; \mathrm{AOA}=35^{\circ}$ the streamlines and static pressure around the sails are decipted in Figure 10,11, 12, and 13. On NACA 0018 sail shape, as the angle of attack increases, the upper area separation of flow moves from the trailing edge towards the leading edge. At the critical angle of attack $15^{\circ}$, upper area flow is more separated, and the NACA 0018 is producing its maximum lift coefficient. As the angle of attack increases further, the upper surface flow becomes more fully separated, and the lift coefficient reduces further.

The flow phenomenon between the port and starboard components of curvy twin sail is different. For port sail, at angle of attack from $5^{\circ}$ to $15^{\circ}$, the improvement of the lower area smooth flow and high velocity flow area between two sails took place due to the formation of high pressure region at the lower area and low pressure region at the area between two sails. The difference between these high and low pressure region cause a lift on the port sail. As the angle of attack increases, the flow separation appears at both lower and area between two sails. It leads to a reduction in flow velocity, which hinders the port sail's ability to create lift. For starboard sail, the stall is caused by flow separation at almost angle of attack, resulting in raising pressure at the upper area, so the adverse lift is created. Consequently, there is a reduction in total lift generated by curvy twin sail. Therefore, the airflow separation at angle of attack $35^{\circ}$, the total lift is able to be maximum. When angle of attack increases from $15^{\circ}$ to $90^{\circ}$, the pressure at the spacing area gradually balances with pressure at the upper area, so the adverse lift reduces to 0 .

Figure 10 shows the velocity streamline and contours on sails at $\mathrm{AOA}=15^{\circ}$. With the curvy twin sails, the flow separation line appears at the upper area. It explains that the pressure at upper area of twin curvy sails is higher than NACA 0018 wing sails, as shown in Figure 11. Besides, the spacing between the port and starboard sails generates the Laval nozzle effect; hence the increase in velocity make a reduction in pressure at this area. Because of curvy shape of port sails, the pressure distribution of twin curvy sails at the lower area is different and higher than NACA 0018 wing sails. 
The high pressure region at the lower area in case 1-1 is more extended than others, so generated lift is better than other cases.

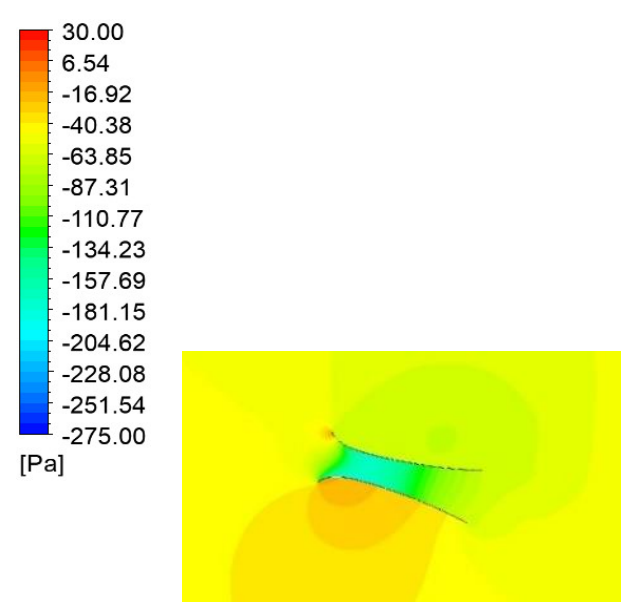

(b)

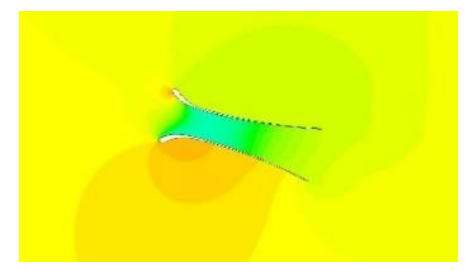

(e)

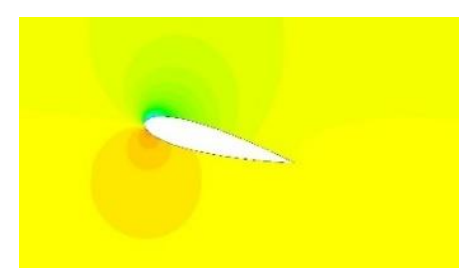

(a)

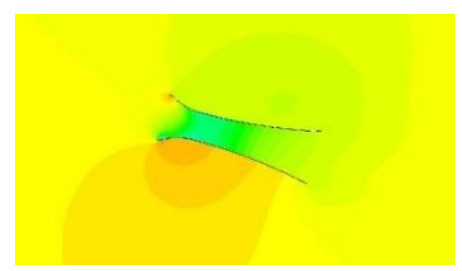

(c)

(d)

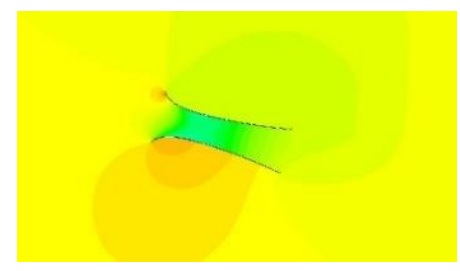

(f)

Figure 11 Pressure contours at $\mathrm{AOA}=15^{\circ}$; (a) NACA 0018; (b) Case 1-1; (c) Case 1-2; (d) Case 1-3; (e) Case 1-4; (f) Case 1-5

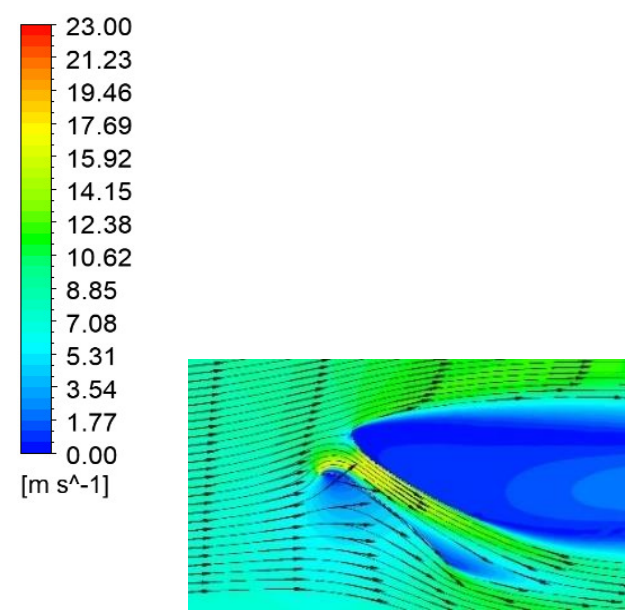

(b)

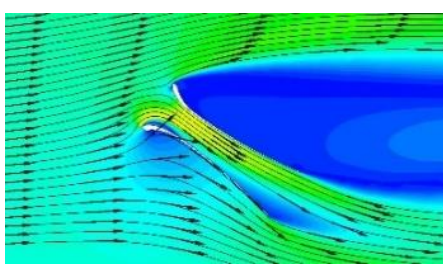

(e)

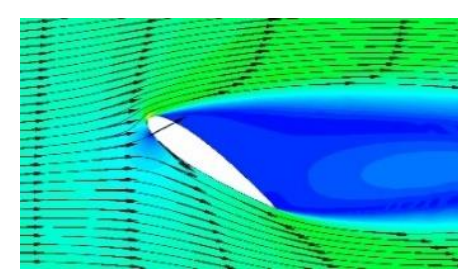

(a)

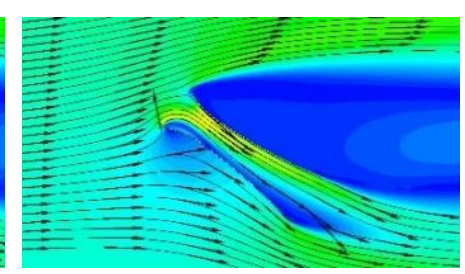

(c)

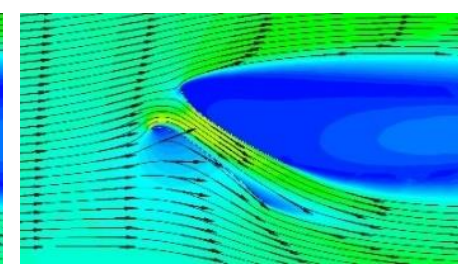

(f)

Figure 12 Velocity contours and streamline at $\mathrm{AOA}=35^{\circ}$; (a) NACA 0018; (b) Case 1-1; (c) Case 1-2; (d) Case 1-3; (e) Case 1-4; (f) Case 1-5 
It can be seen from Figure 12 that the upper area of curvy twin sails has a large flow separation at $\mathrm{AOA}=35^{\circ}$, and the opening of this area is unnoticeable in comparison with the NACA 0018 wing sail. This phenomenon leads to similar pressure at the upper area, as shown in Figure 13. Nevertheless, the Laval effect still occurs at the area between two sails, the low pressure region maintained. The low velocity at the lower area of curvy twin sails created a higher pressure than the NACA 0018 wing sail. Consequently, the lift generated by curvy twin sails is more effective than NACA 0018 wing sails.
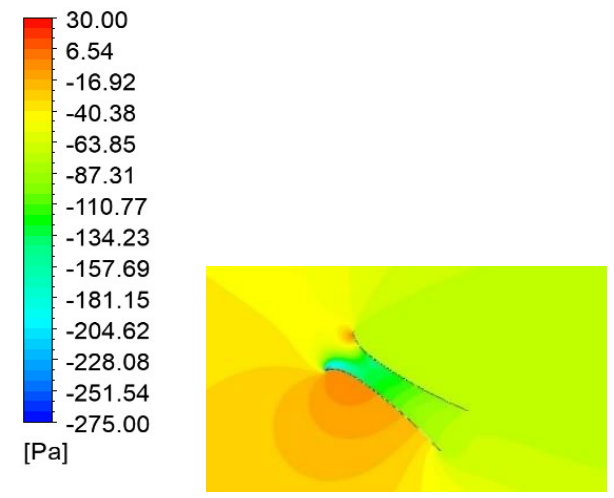

(b)

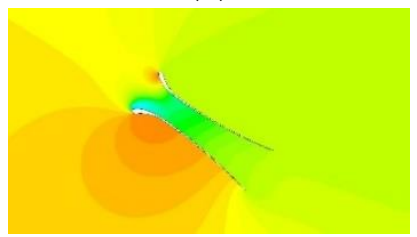

(e)

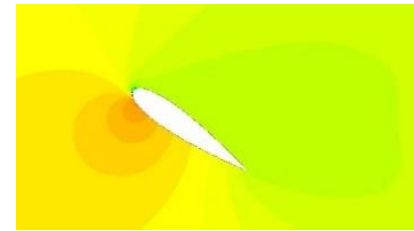

(a)

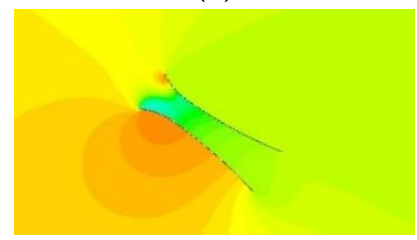

(c)

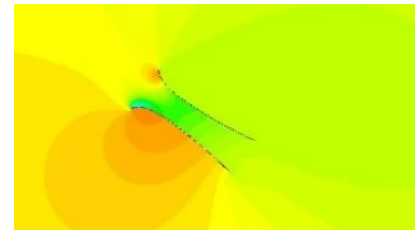

(f)

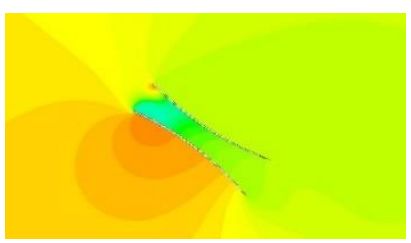

(d)

Figure 13 Pressure contours at AOA = 35; (a) NACA 0018; (b) Case 1-1; (c) Case 1-2; (d) Case 1-3; (e)

Case 1-4; (f) Case 1-5

The flow separation appears at the starboard sail's upper area for curvy twin sails at almost angle of attack. With the increase in angle of attack, the flow separation of starboard sail of the curvy twin sails expands and becomes larger. It is explained that raising in pressure at the upper area of the starboard sail creates adverse lift. The lift generated in case 1-1 reaches at peak at $\mathrm{AOA}=35^{\circ}$ and a little higher than other cases. Because of the curvy shape, the lower area and area between the two sails flow characteristics are different. The smoother flow at the area between two sails in case 1-1 causes lower pressure, as shown in figure 13. This phenomenon leads to little lift improvement in case 1-1 in comparison with other cases.

\subsubsection{Driving force coefficient comparison}

When the true wind direction $\left(\mathrm{V}_{\mathrm{T}}\right)$ is constant and sailing drone permit sailing at constant speed $(\mathrm{Vs})$, the relative wind acting on sails is called apparent wind $\left(\mathrm{V}_{\mathrm{A}}\right)$ as illustrated in figure 14.

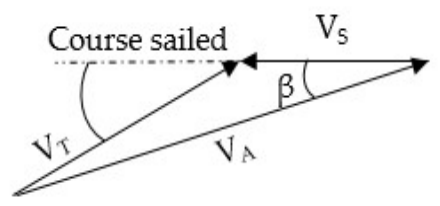

Figure 14 The velocity triangle

The relationship among true wind, sailing drone speed and apparent wind is give equations (14, 15):

$$
\mathrm{V}_{\mathrm{A}}=\sqrt{\mathrm{V}_{\mathrm{T}}^{2}+\mathrm{V}_{S}^{2}+2 \mathrm{~V}_{\mathrm{T}} \mathrm{V}_{\mathrm{S}} \cos \gamma}
$$




$$
\beta=\operatorname{arcos}\left(\frac{\mathrm{V}_{\mathrm{T}} \cos \gamma+\mathrm{V}_{\mathrm{S}}}{\mathrm{v}_{\mathrm{A}}}\right)
$$

To investigate the effect of the flow interaction, which has a significant effect on sail's aerodynamic performance, a range of numerical aerodynamic analyses were conducted for sails by varying the true wind direction from $0^{\circ}$ to $180^{\circ}$ in intervals of $5^{\circ}$. It is supposed that sailing drone permit sailing at course sailed direction and $\mathrm{Vs}=0 \mathrm{~m} / \mathrm{s}$. Therefore, the apparent wind is equal to the true wind.

The requirement in generating driving force at port side and starboard side working conditions is similar, so the symmetric design of curvy twin sail is applied. The apparent wind direction is determined from $0^{\circ}$ to $180^{\circ}$; the lift and drag generated by sail are calculated. These forces are resolved into driving force $\left(\mathrm{F}_{\mathrm{R}}\right)$ and the heeling force $\left(\mathrm{F}_{\mathrm{H}}\right)$. The driving force is maximized, corresponding with each certain apparent wind angle. For certain apparent wind speed and angle, the angle of attack adjusted to generate different driving force values, and the maximum driving force is determined. Suppose that the heeling force $\left(\mathrm{F}_{H}\right)$ is equal to horizontal side force $(\mathrm{Fs})[16,17]$. For apparent wind angles aligned with the entry point of the sail, the sail lift is the predominant component of propulsion. For apparent wind angles behind the sail, lift diminishes, and drag increases as the predominant component of propulsion. The driving force coefficient in all sail designs is illustrated in Figure 15. It is shown that the curvy twin sail is more effective than NACA 0018 wing sail in terms of the driving force.
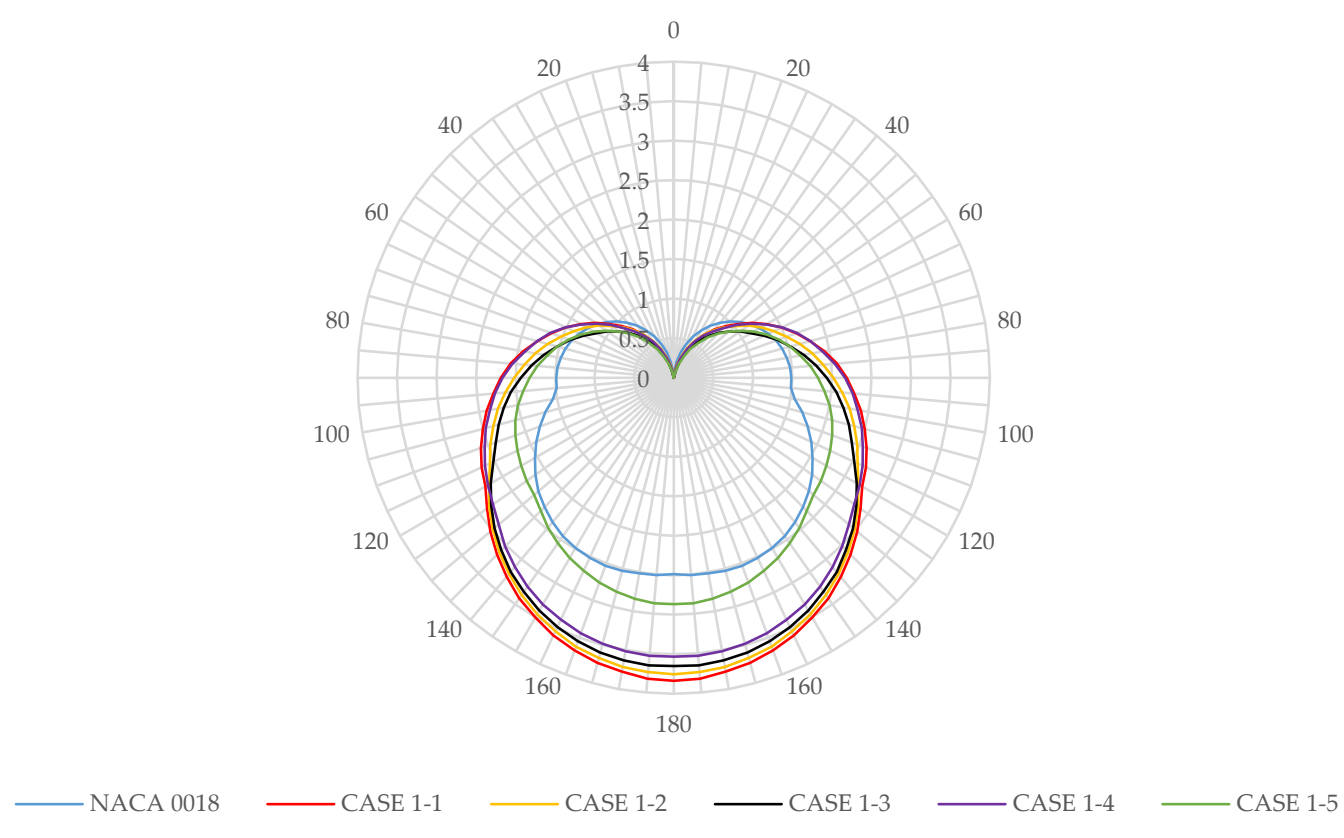

Figure 15 Driving force coefficient

The driving force is totally calculated by drag and lift. At the most angle of attack, the drag and lift of curvy twin sail are higher than NACA 0018 sail, so the generated driving force is improved. The case 1-1 curvy twin sail is found that the driving force was more effective than NACA 0018 sail at the apparent wind angle from $20^{\circ}$ to $180^{\circ}$. Moreover, the case $1-1$ curvy twin sail is able to generate a greater driving force than other cases. The reason for this phenomenon is attributed to the higher lift and drag coefficient at the different angles of attack. Although the lift and drag ratio is not improved, the lift coefficient development of curvy twin sail can make a driving force improvement.

\subsection{Spacing optimizations}

The two dimensional flow around the curvy twin sail at different spacing $S$ values is studied in detail. In order to better study the effect of the spacing on aerodynamic characteristics and established 
stall of the curvy twin sail, we analyzed the lift and drag characteristics when the spacing is changed, as shown in Table 6.

Table 6. Spacing optimizations

\begin{tabular}{cc}
\hline Spacing optimization case & S \\
\hline Case 2-1 & $0.035 \mathrm{~L}$ \\
\hline Case 2-2 & $0.07 \mathrm{~L}$ \\
\hline Case 2-3 & $0.14 \mathrm{~L}$ \\
\hline Case 2-4 & $0.21 \mathrm{~L}$ \\
\hline Case 2-5 & $0.28 \mathrm{~L}$ \\
\hline Case 2-6 & $0.35 \mathrm{~L}$ \\
\hline
\end{tabular}

\subsubsection{Aerodynamic Performance}

Figure 16 shows the lift and drag characteristics for different spacing. The spacing has little effect on the lifts and drags coefficient with AOA from $50^{\circ}$ to $90^{\circ}$. The lift coefficient first increases and then reduces with the of spacing extension, especially AOA from $10^{\circ}$ to $30^{\circ}$. As the discussion in shape optimization, the critical angle of attack in case of the curvy twin sail depends on the relationship between lift of the port and starboard sails, so the total lift coefficient at vary spacing optimization is different. The critical angle of attack in case 2-1 and 2-2 is $45^{\circ}$, while in case 2-3, 2-4 is $35^{\circ}$, and case 2$5,2-6$ is $30^{\circ}$. The further angle of attack increases, the upper area flow becomes more fully separated, and lift coefficient reduces further.

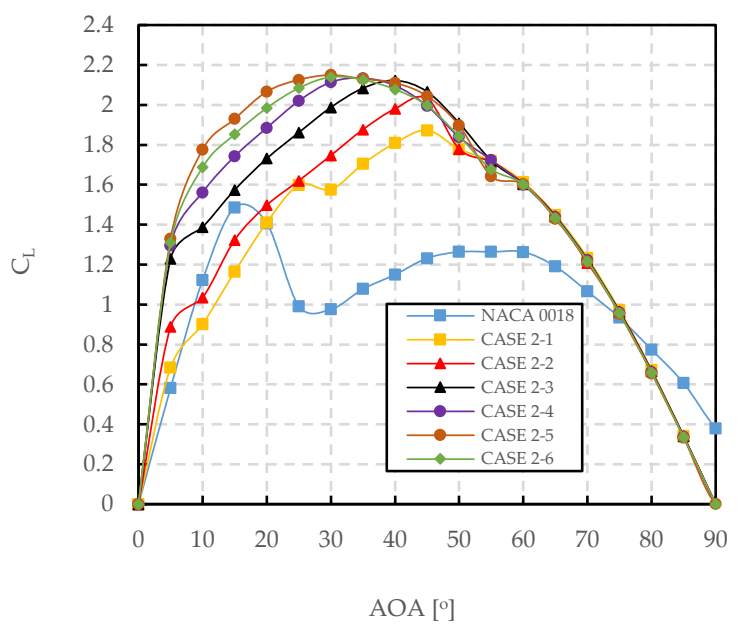

(a)

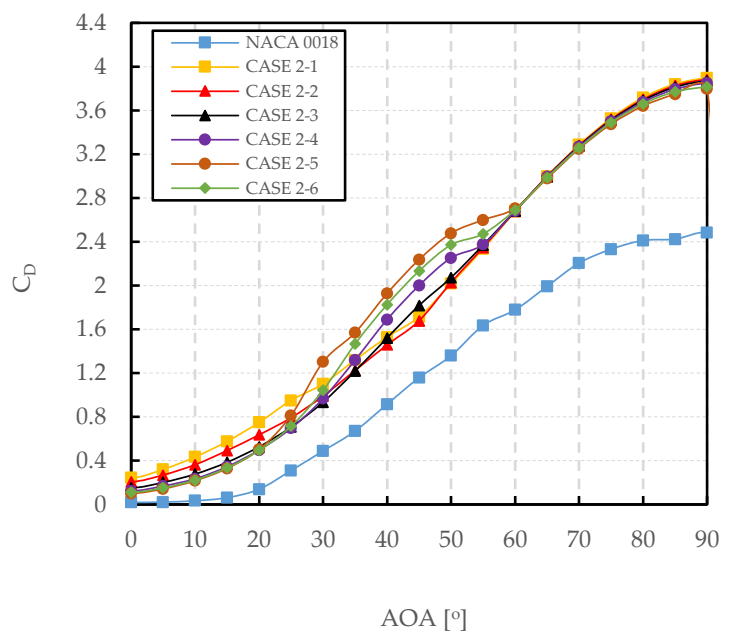

(b)

Figure 16 Effect of spacing modifications on lift and drag coefficients

(a) Lift coefficient; (b) Drag coefficient

\subsubsection{Velocity streamline and pressure contour}

As for the curvy twin sail with different spacing values at $\mathrm{AOA}=15^{\circ}$ and $25^{\circ}$, the streamlines and static pressure around the sails are depicted in Figures 17, 18, 19, and 20. As the velocity streamlines shown, although the velocity flow at the area between two sails increases when the spacing $S$ reduces and leading to a lower pressure region, the upper area separation point of flow is more significant. As a result of the curvy twin sails' upper area flow is more stall, the higher pressure region is formed above the sail. These higher pressure regions reduce the differential pressure causing a lower lift force. 


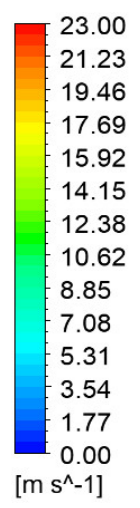

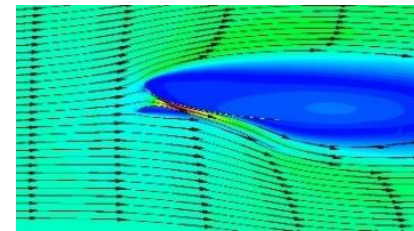

(b)

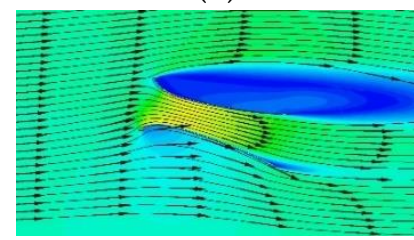

(e)

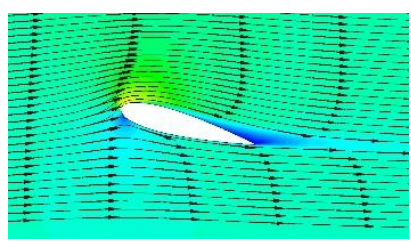

(a)

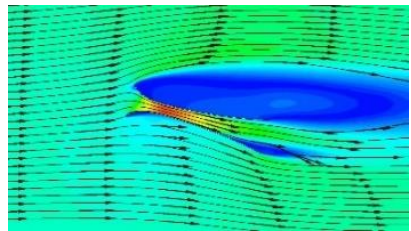

(c)

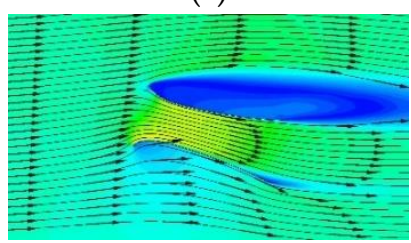

(f)

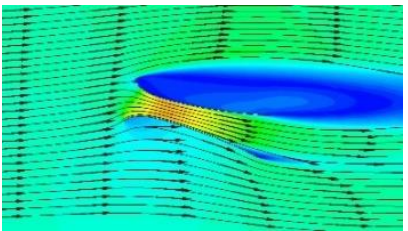

(d)

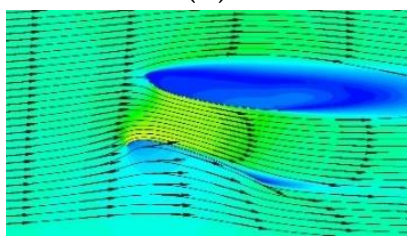

(g)

Figure 17 Velocity contours and streamline at $\mathrm{AOA}=15^{\circ}$; (a) NACA 0018; (b) Case 2-1; (c) Case 2-2;

(d) Case 2-3; (e) Case 2-4; (f) Case 2-5; (g) Case 2-6

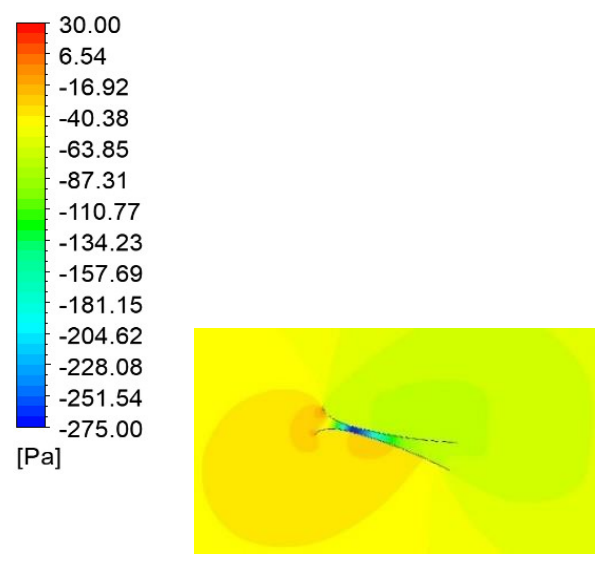

(b)

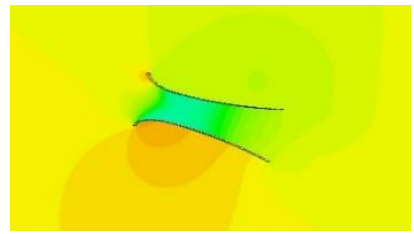

(e)

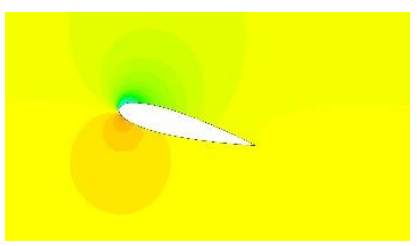

(a)

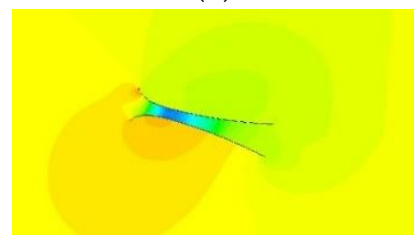

(c)

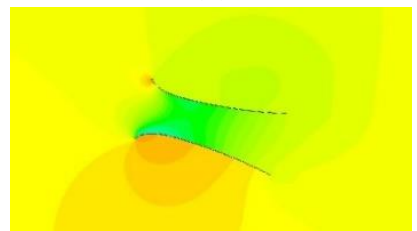

(f)

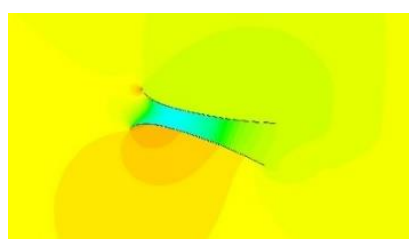

(d)

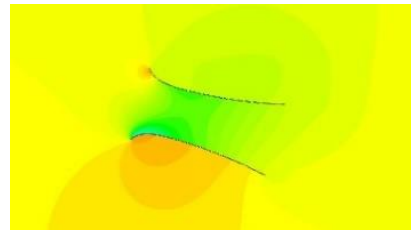

(g)

Figure 18 Pressure contours at $\mathrm{AOA}=15^{\circ}$; (a) NACA 0018; (b) Case 2-1; (c) Case 2-2; (d) Case 2-3; (e) Case 2-4; (f) Case 2-5; (g) Case 2-6

Figure 17 illustrates the velocity streamlines and contours on sails at $\mathrm{AOA}=15^{\circ}$. With the increase in spacing $S$ from $0.035 \mathrm{~L}$ to $0.14 \mathrm{~L}$, the upper area's flow separation narrows considerably. However, the upper area's flow separation is unchanged when the spacing $S$ is over $0.14 \mathrm{~L}$. It explains that the pressure at the upper area in case $2-1 ; 2-2 ; 2-3$ is higher than in case $2-4 ; 2-5 ; 2-6$, as shown in Figure 18. Although the smaller spacing between the port and starboard sails is chosen, the higher velocity flow is generated. The vortex appeared in case 2-1;2-2; 2-3 leads to a reduction in lift coefficient. 


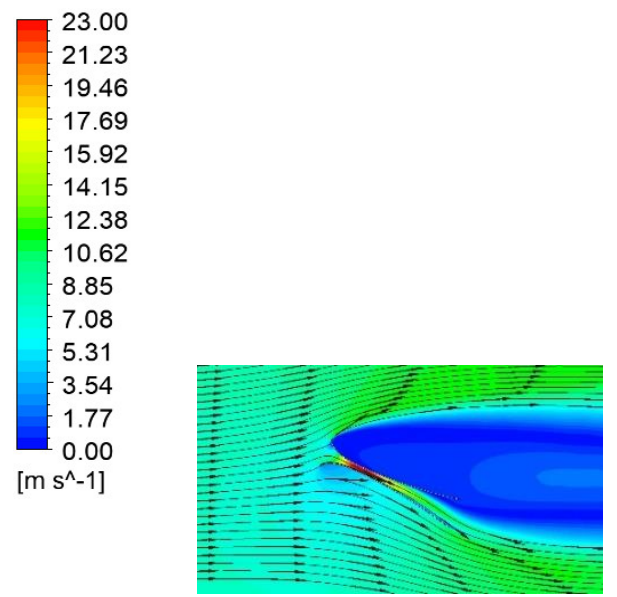

(b)

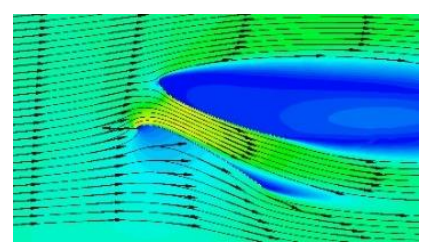

(e)

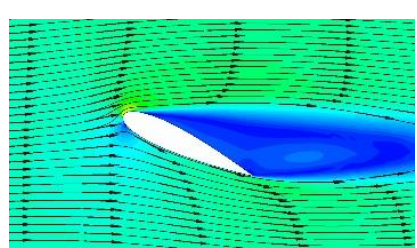

(a)

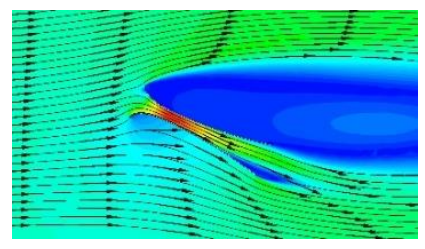

(c)

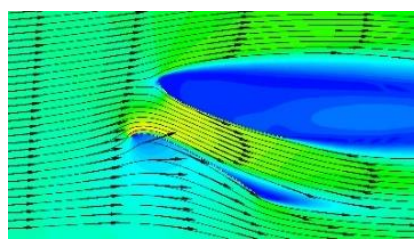

(f)

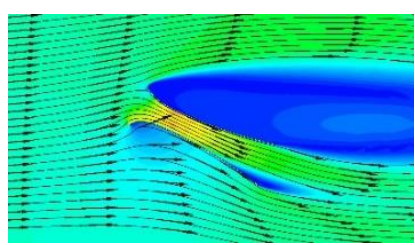

(d)

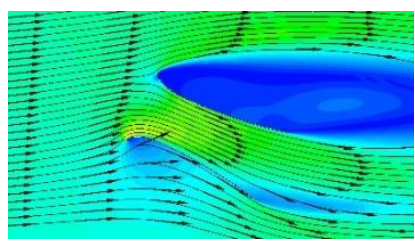

(g)

Figure 19 Velocity contours and streamline at $\mathrm{AOA}=25^{\circ}$; (a) NACA 0018; (b) Case 2-1; (c) Case 2-2;

(d) Case 2-3; (e) Case 2-4; (f) Case 2-5; (g) Case 2-6

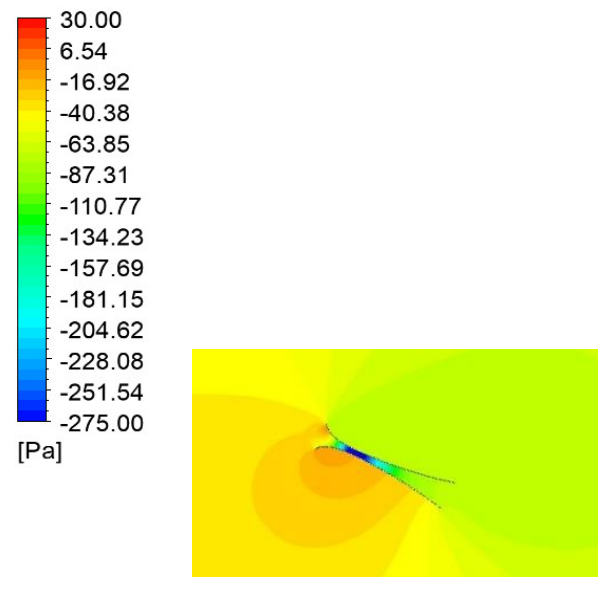

(b)

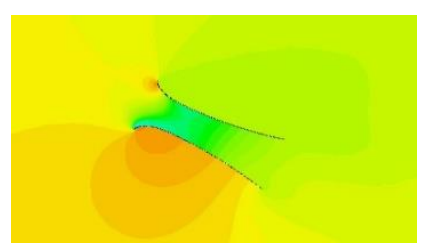

(e)

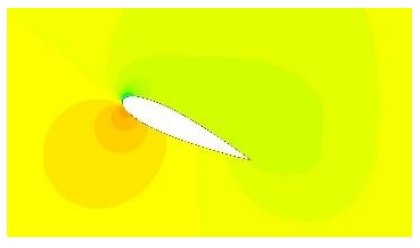

(a)

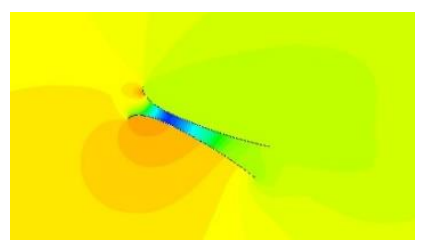

(c)

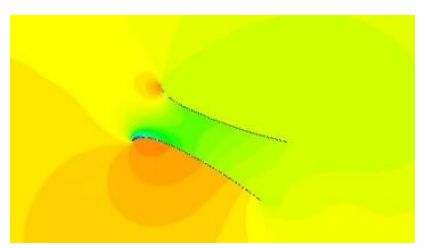

(f)

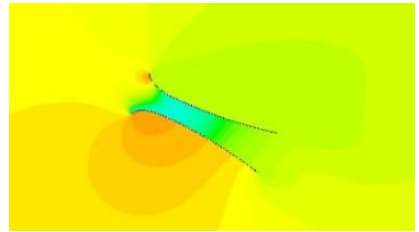

(d)

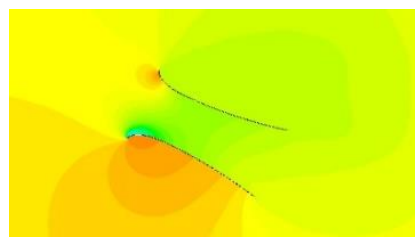

(g)

Figure 20 Pressure contours at $\mathrm{AOA}=25^{\circ}$; (a) NACA 0018; (b) Case 2-1; (c) Case 2-2; (d) Case 2-3; (e) Case 2-4; (f) Case 2-5; (g) Case 2-6

It can be seen from Figure 19 that the upper area of sails in case 2-1 has the largest flow separation at $\mathrm{AOA}=25^{\circ}$ in comparison with other cases. Although the twin curvy sails shape in spacing optimization is similar, the spacing effects on the flow at the lower area of the curvy twin sail. The 
spacing $0.28 \mathrm{~L}$ show the maximum high pressure region at lower area and the small low pressure area at leading edges, so the higher lift force is generated in comparison with other spacing value, as shown in Figure 20.

\subsubsection{Driving force coefficient comparison}

To further verify the driving force performance of curvy twin sail, the lift and drag coefficients are converted to the driving force coefficients, as illustrated in Figure 21. When the apparent wind angle is less the $20^{\circ}$, the spacing $0.035 \mathrm{~L}$ and $0.07 \mathrm{~L}$ twin curvy sails and NACA 0018 wing sail are unable to generated driving force. In contrast, the spacing $0.28 \mathrm{~L}$ and $0.35 \mathrm{~L}$ twin curvy sail can generate driving forces from $10^{\circ}$ to $180^{\circ}$. Moreover, the case $2-5$ corresponding with spacing $0.28 \mathrm{~L}$ is found that the driving force is most effective.

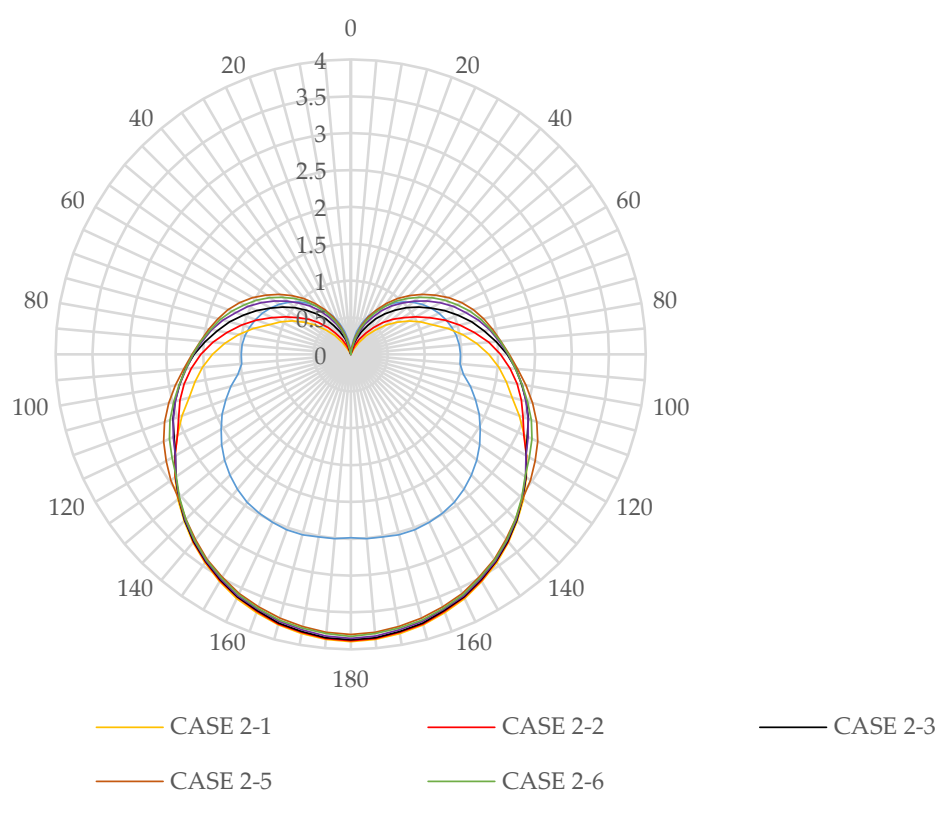

Figure 21 Driving force coefficient

\section{Conclusions}

This study investigated the proposed curvy twin sail and compared it with the NACA 0018 wing sail on the aerodynamic performance. Since sail shape and the spacing between two sail components were used to introduce as optimized parameters. The CFD two dimensional model was generated by using CFD commercial code and validated by published experimental data. The lift, drag, and driving force coefficients were obtained using the same Reynolds number.

The shape optimization results show that the port sail mainly creates the favorable lift force while the starboard sail makes an adverse lift in starboard wind conditions. The port and starboard sails' function is interchangeable in port wind conditions, so the symmetric design is a requirement for the curvy twin sail. When the sail shape changed, the flow separation phenomenon appeared around the sail is considerable. The curvy twin sail showed the performance improvement in lift, drag, and driving force coefficient. This improvement can be attributed to the airstream appearance between two sail components and their curvy shape.

The spacing optimization mainly studies the influence of the spacing on the aerodynamic characteristics of curvy twin sail. When the spacing is $0.035 \mathrm{~L}, 0.07 \mathrm{~L}$ and $0.14 \mathrm{~L}$, the stall has been dramatically affected the lift coefficient reduction, while flow separation improvement with spacing is $0.21 \mathrm{~L}, 0.28 \mathrm{~L}$ and $0.35 \mathrm{~L}$. Especially, the spacing $0.28 \mathrm{~L}$ shows the maximum high pressure at lower area and the small low pressure area at leading edges, so the higher lift is generated compared to other spacing values. 
Author Contributions: Conceptualization, P.M.N. and C.Y.; investigation, P.M.N and C.Y.; methodology, P.M.N. and I.R; software. P.M.N and B.K; writing - original draft preparation, P.M.N. and I.R; writing - review and editing, P.M.N and B.K; supervision, C.Y. All authors have read and agreed to the published version of the manuscript.

Funding: This research was funded by Ministry of Trade, Industry and Energy (project titled “A Development of Suitable Sail Drone for Korea Coast", Project No. KOITA - CLUSTER - 2020 - 08.

Conflict of Interest: The authors declare no conflict of interest.

\section{References}

1. Elkaim, G. System identification for precision control of wing-sailed GPS-guided catamaran. Stanford University, 2001.

2. Neal,M.,\& Saauze, C. Design considerations for sailing robots performing long-term autonomous oceanography. Austrian Journal of Artificial Intelligence, 2008; vol. 2, pp. 4 - 10.

3. Elkaim, G. Experimental aerodynamic performance of self-trimming wing-sail for autonomous surface vehicles, 2007.

4. Alves, J.C; Thomas, B.M.; Neal \& Sauze, C. Technologies for Autonomous Sailing, Aberystwyth University, UK, 2008.

5. Jenkins, R., Meinig, C., Lawrence-Slavas, N., \& Tabisola, H. M. The Use of Sail-drones to Examine Spring Conditions in the Bering Sea: Vehicle Specification and Mission Performance. OCEANS 2015 - MTS/IEEE Washington. Retrieved 01 17, 2017.

6. Seifert, A.; Bachar, T.; Koss, D.; Shepshelovich, M.; Wygnanski, I. Oscillatory Blowing: A Tool to Delay Boundary-Layer Separation. AIAA J. 1993, 31, pp. 2052-2060.

7. Kuttenkeuler, J; Mikael, R. Design of free-rotating wing sail for autonomous sailboat, KTH Royal Institute of Technology, Sweden, 2017.

8. Borglund, D.; Kuttenkeuler, J. Active Wing Flutter Suppression Using a Trailing Edge Flap. J. Fluids Struct. 2002, 16, pp. 271-294.

9. Daniel, W.A. The CFD Assisted Design and Experimental Testing of a Wingsail with High Lift Devices; University of Salford: Salford, UK, 1996.

10. Carr, L.W.; McAlister, K.W. The effect of a leading-edge slat on the dynamic stall of an oscillating airfoil. AIAA Pap. 1983, 83, 2533.

11. Li, Q.; Nihei, Y.; Nakashima, T.; Iked, Y. A study on the performance of cascade hard sails and sailequipped vessels. Ocean Eng. 2015, 98, pp. 23-31.

12. Fish, F.E.; Battle, J.M. Hydrodynamic design of the humpback whale flipper. J. Morphol. 1995, 225, pp. 5160.

13. Gasser, E.Hassan; Amany, Hassan; M. Elsayed Youssef. Numerical Investigation of Medium Range Reynold Number Aerodynamics Characteristics for NACA0018 airfoil. CFD letter, 175-18, 2014.

14. Graf K., Bohem C., Ranzsch H., 'CFD- and VPP-Challenges in the Design of the New AC90 America's Cup Yacht', in the proceedings of the 19th Chesapeake Sailing Yacht Symposium, Annapolis, USA, March 20th21st, 2009, pp. 1-17.

15. Braun J.B., 'High Fidelity CFD Simulations in Racing Yacht Aerodynamic Analysis', in the proceedings of the 3 rd High Performance Yacht Design Conference, pp. 168-175, Auckland, New Zealand, December 2nd4th, 2008.

16. Hutchins N., 'The Use of Ansys CFX in America's Cup Yacht Design', in the proceedings of the 3rd High Performance Yacht Design Conference, Auckland, New Zealand, December 2nd-4th, 2008, pp. 185-192.

17. Milgram J.H., 'The Aerodynamics of Sails', In the proceedings of the 7th Symposium of Naval Hydrodynamic, 1968, pp. 1397-1434.

18. Gentry A.E.,'The Application of Computational Fluid Dynamics to Sails', in proceedings of the Symposium on Hydrodynamic Performance Enhancement for Marine Applications, Newport, Rhode Island, USA, 1988.

19. Fallow J.B., 'America's Cup Sail Design', Journal of Wind Engineering and Industrial Aerodynamics, 1996, 63, pp. 183-192.

20. Claughton A.R., Campbell I.M.C., 'Wind Tunnel Testing of Sailing Rigs', in the proceedings of the International HISWA Symposium on Yacht Design and Yacht Construction, Amsterdam, November 14th15th, 1994, pp. 89-106. 
21. Hedges K.L., 'Computer Modelling of Downwind Sails', ME Thesis, University of Auckland, New Zealand, 1993.

22. Hedges K.L., Richards P.J., Mallison G.D., 'Computer Modeling of Downwind Sails', Journal of Wind Engineering and Industrial Aerodynamics, 63, 1996, pp. 95-110.

23. Rumsey, Christopher A., Eggert and Christopher L., 'CFD Study of NACA 0018 Airfoil with Flow Control, NASA, 2017. 